\title{
Clarification of red raspberry juice using microfiltration with gas backwashing: A viable strategy to maximize permeate flux and minimize a loss of anthocyanins
}

\author{
Goran T. Vladisauljevićc ${ }^{a, b, *}$, Predrag Vukosavljevićc ${ }^{c}$ Mile S. Veljovićc \\ a Chemical Engineering Department, Loughborough University, Loughborough, Leicestershire LE11 3TU, UK \\ $\mathrm{b}^{\mathrm{b}}$ Laboratory of Chemical Dynamics and Permanent Education, Vinča Institute of Nuclear Sciences, University of Belgrade, P.O. Box 522, \\ 11001 Belgrade, Serbia \\ ' Institute of Food Technology and Biochemistry, Faculty of Agriculture, University of Belgrade, P.O. Box 127, 11081 Zemun-Belgrade, \\ Serbia
}

\begin{abstract}
A B S T R A C T
Red raspberry (Rubus idaeus) juice was produced by maceration of raspberry pulp at $50^{\circ} \mathrm{C}$ for $2 \mathrm{~h}$ using $400 \mathrm{mg} \mathrm{kg}^{-1}$ Klerzyme ${ }^{\circledR} 150$ enzymatic pectolitic preparation followed by raw juice clarification with gelatin and bentonite or crossflow membrane filtration. A minimal loss of anthocyanins from 630 to $540 \mathrm{mgl}^{-1}$ was obtained when the juice was clarified using a ceramic multichannel microfilter (MF) with a pore size of $0.2 \mu \mathrm{m}$. A light transmission at $625 \mathrm{~nm}$ in MF permeate was above $85 \%$ and the residual pectin $\left(900 \mathrm{mgl}^{-1}\right)$ was completely removed. During ultrafiltration through ceramic or polysulfone membranes with a molecular weight cut-off of $30-300 \mathrm{kDa}$, the content of anthocyanins was reduced to $220-370 \mathrm{mgl}^{-1}$, but a light transmission at $625 \mathrm{~nm}$ was as high as $96 \%$. The permeate flux in MF was maintained at high values above $170 \mathrm{~lm}^{-2} \mathrm{~h}^{-1}$ at 3 bar for more than $2 \mathrm{~h}$ by backwashing the membrane with a compressed air every $6 \mathrm{~min}$ for $1 \mathrm{~min}$. The cake compression at high pressures was avoided by short filtration times between backwashing.
\end{abstract}

(c) 2013 The Institution of Chemical Engineers. Published by Elsevier B.V. All rights reserved.

Keywords: Microfiltration; Ultrafiltration; Red raspberry juice; Clarification; Anthocyanin

\section{Introduction}

Red raspberries (Rubus idaeus L.) are produced in 37 countries worldwide on about 184,000 acres with a global production estimated at over 400,000 tons per year. Only about $3 \%$ of red raspberries are sold fresh and the rest are processed into juices and other products such as jams, jellies, confectionery products, and yogurts. Red raspberry juice is a rich source of phenolic compounds with antioxidant capacity, such as anthocyanins and elagitannins (Weber et al., 2001; Suh et al., 2011; Mejia-Meza et al., 2010). Phenolic compounds from red raspberries show strong antimicrobial properties and can selectively inhibit the growth of intestinal pathogens, especially Staphylococcus strains (Puupponen-Pimiä et al., 2005). Consumption of red raspberry juice has been shown to lead to a marked reduction in aortic lipid deposition, which can help to prevent the development of early atherosclerosis (Suh et al., 2011; Rouanet et al., 2010). Red raspberry juice may also have beneficial effects against several types of human cancers, which is attributed to its ability to reduce damage resulting from oxidative stress and inflammation (Seeram, 2008; ZafraStone et al., 2007).

Red raspberry juice is usually stored and traded in the form of a clear juice concentrate to reduce the storage and transportation costs. A cloudy juice can be clarified by flocculation of suspended solids with fining agents, such as gelatin and bentonite (Benitez and Lozano, 2007) or using membrane filtration. Compared to traditional processing with fining agents that require subsequent diatomaceous earth filtration, ultrafiltration (UF) or microfiltration (MF) entirely eliminates the

* Corresponding author at: Chemical Engineering Department, Loughborough University, Loughborough, Leicestershire LE11 3TU, UK. Tel.: +44 01509222 518; fax: +4401509223923.

E-mail address: G.Vladisavljevic@lboro.ac.uk (G.T. Vladisavljević).

Received 6 January 2013; Received in revised form 24 April 2013; Accepted 2 May 2013

0960-3085/\$ - see front matter @ 2013 The Institution of Chemical Engineers. Published by Elsevier B.V. All rights reserved. http://dx.doi.org/10.1016/j.fbp.2013.05.004 
use of diatomaceous earth and fining agents, the consumption of pectolitic enzymes is reduced because enzymes can be recycled, and the total processing time can be significantly shortened (Girard and Fukumoto, 2000).

The major problem in the operation of UF and MF in the fruit juice industry is membrane fouling, which leads to a significant reduction in permeate flux with time (Mondor et al., 2000). In order to control membrane fouling and maximize permeate flux during juice clarification, several flux enhancement methods have been studied including periodic backwash with air or $N_{2}$ (Su et al., 1993; Padilla-Zakour and McLellan, 1993), pressure and flow pulsations superimposed on a steady operating pressure (Gupta et al., 1992), gas sparging, i.e. injection of gas bubbles into the feed stream (Laorko et al., 2011), insertion of turbulence promoters in the feed channel (Pal et al., 2008), application of electric field in constant or pulsed mode (Sarkar et al., 2008a,b), and implementation of various juice pretreatment methods, such as fining treatment with gelatin and bentonite (Rai et al., 2007) and treatment with various filter aids (Youn et al., 2004).

In the past several decades, UF and MF have been increasingly investigated for clarification of juices of different fruits including apple (Vladisavljević et al., 2003), blackcurrant (Pap et al., 2012), sour cherry (Wang et al., 2005), pear (Kirk et al., 1983), melon and watermelon (Vaillant et al., 2005; Rai et al., 2010), kiwifruit (Cassano et al., 2008), passion fruit (Vaillant et al., 1999), starfruit (Sulaiman et al., 1998), orange and lemon (Rai et al., 2007; Espamer et al., 2006), grapefruit (Snir et al., 1995), mango (Vaillant et al., 2001), banana, pineapple and blackberry (Vaillant et al., 2008), chokeberry and redcurrant (Koroknai et al., 2008), grape (Rektor et al., 2004), peach (Brenna et al., 2000) and plum (Ushikubo et al., 2007).

However, to the best of our knowledge, there has been no previous research on using MF and UF to the clarification of red raspberry juice. The objectives of this study were: (i) to compare the quality of red raspberry juice clarified using conventional methods and UF or MF; (ii) to estimate the changes of color during production of fresh and reconstituted red raspberry juice; (iii) to investigate the effects of operating parameters and periodic gas backwash on the permeate flux during MF of red raspberry juice using a ceramic membrane.

\section{Materials and methods}

\subsection{Juice manufacturing process}

Red raspberry juice was produced from a Villamete variety using the manufacturing process shown in Fig. 1. Fruit was first defrosted and crushed to a pulp (sample 1). The pulp was heated at $90^{\circ} \mathrm{C}$ for $2 \mathrm{~min}$ to destroy the endogenous polyphenol oxidase. If not inactivated, this enzyme can cause the oxidation of monophenols and o-diphenols in the fruit to oquinones, which then undergo non-enzymatic polymerization or condensation reactions, leading to decolorizing and browning (Yoruk and Marshall, 2003). The pulp was then cooled down to $50^{\circ} \mathrm{C}$ for a single-stage enzymatic maceration (Aehle, 2007). The maceration was performed at $50^{\circ} \mathrm{C}$ for $2 \mathrm{~h}$ using $400 \mathrm{mg} \mathrm{kg}^{-1}$ pectinase preparation produced from Aspergillus niger (Klerzyme ${ }^{\circledR} 150$, DSM, Lill, France). Pectinases were used to increase juice yield and accelerate juice clarification. After that, the pulp was pressed in a hydraulic press with a volume of 51 under a pressure of 150 bar to extract juice (sample 2). A cotton bag filter with a pore size of about $20 \mu \mathrm{m}$ was used to

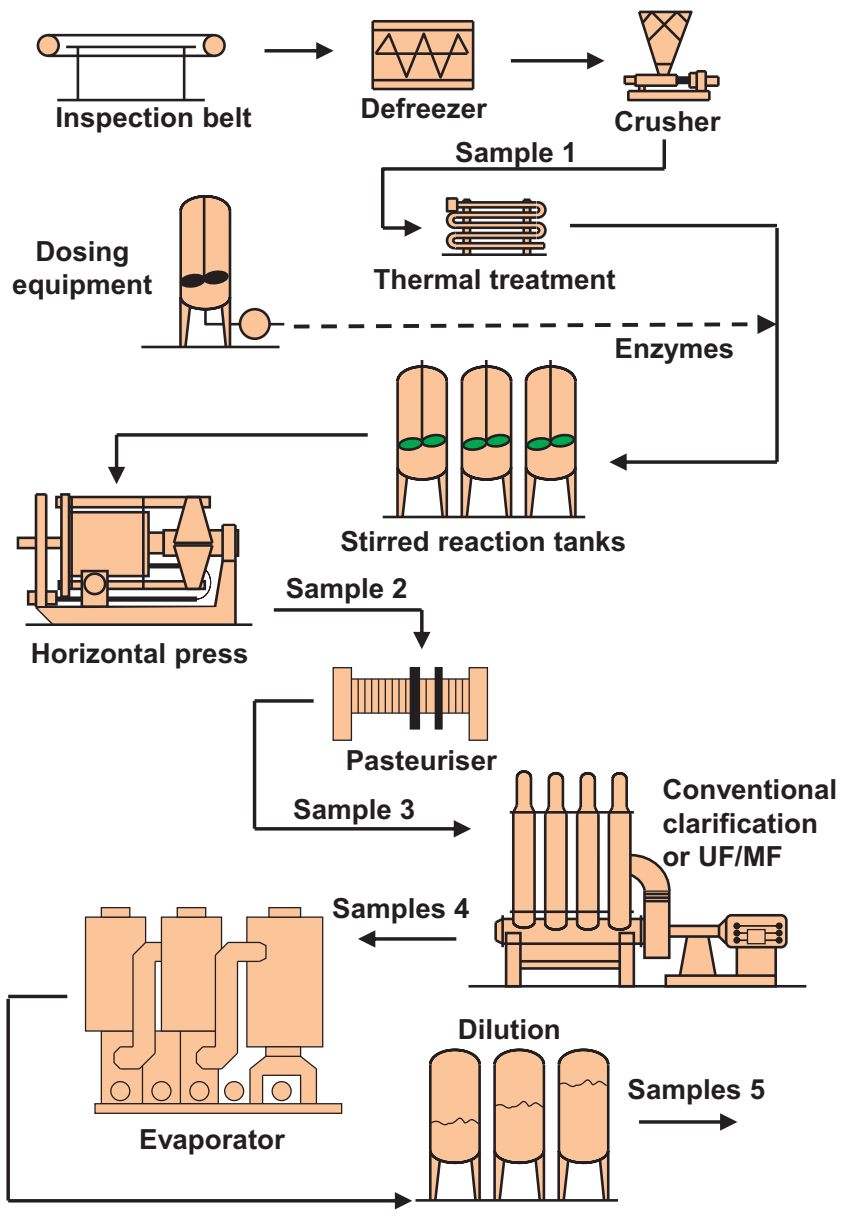

Fig. 1 - A scheme of the manufacturing process used in this work for red raspberry processing in clear juice concentrate using conventional clarification or membrane filtration (MF or UF). A light transmittance at $625 \mathrm{~nm}$ in samples 4 and the amount of total anthocyanins in samples 1-5 are given in Figs. 3 and 4, respectively.

retain the pulp in the press. A juice yield during pressing was $89.2 \%$, which means that $89.2 \mathrm{~kg}$ of a raw juice was extracted per $100 \mathrm{~kg}$ of pulp. The juice was tested for pectin using the alcohol test and a result was negative. The juice was then pasteurized at $90^{\circ} \mathrm{C}$ to denature the proteins, followed by fast cooling to allow denatured proteins to precipitate.

A pasteurized raw juice (sample 3 ) was clarified using seven different methods, namely fining with $36 \mathrm{mgl}^{-1}$ gelatin and $1000 \mathrm{mgl}^{-1}$ bentonite (sample 4a), fining with $65 \mathrm{mgl}^{-1}$ gelatin and $1000 \mathrm{mgl}^{-1}$ bentonite (sample $4 \mathrm{~b}$ ), UF using a $300-\mathrm{kDa}$ Carbosep M9 membrane (sample 4c), UF using a 50-kDa Carbosep M8 membrane (sample 4d), UF using a 30-kDa Carbosep M7 membrane (sample 4e); UF using a 30-kDa polysulfone hollow fiber membrane (sample 4f), and MF using a $0.2-\mu \mathrm{m}$ pore size Kerasep W5 membrane (sample $4 \mathrm{~g}$ ). The clarified juice was evaporated from 9 to $60^{\circ} \mathrm{Bx}$ at a pressure of 0.1 bar, corresponding to the boiling point of $46^{\circ} \mathrm{C}$. The concentration of solids in the juice after evaporation was similar to typical Brix levels in a commercial red raspberry concentrate of $60-65^{\circ} \mathrm{Bx}{ }^{\prime \prime}$. Finally, the juice concentrate produced using different clarification methods was diluted with distilled water back to its original strength of $9.4^{\circ} \mathrm{Bx}$ (samples 5) in order to compare the loss of anthocyanins in the fresh and reconstituted juice samples. 


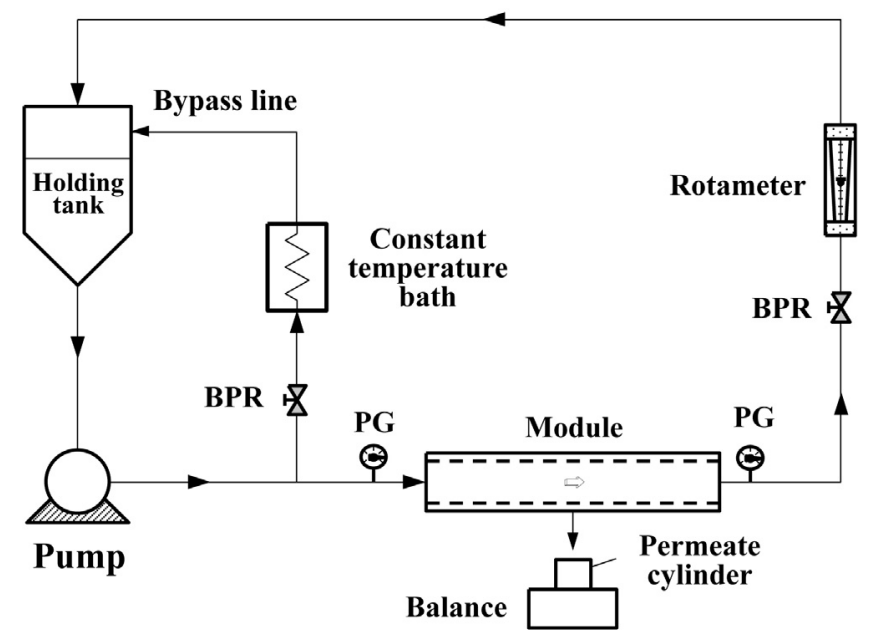

Fig. 2 - Schematic diagram of microfiltration/ultrafiltration rig used in this work (PG - pressure gauge, BPR back-pressure regulator).

\subsection{Membranes}

UF was carried out using inorganic Carbosep ${ }^{\circledR}$ M9, M8, and M7 membranes (Tech-Sep, Miribel, France) with a molecular weight cut-off (MWCO) of 300, 50 and $30 \mathrm{kDa}$, respectively and a polysulfone hollow fiber membrane (Ultraflux ${ }^{\circledR}$ AV 1000 S, Fresenius Medical Care, Germany) with a 30-kDa MWCO. Carbosep tubular membranes consisted of a single cylindrical tube of $10 \mathrm{~mm}$ external diameter and $6 \mathrm{~mm}$ internal diameter. The active layer was composed of a thin layer of zirconium dioxide and titanium dioxide supported by a porous carbon substructure. The membrane was installed inside a cylindrical stainless steel module, which provided an effective membrane length of $225 \mathrm{~mm}$ and an effective membrane area of $42.4 \mathrm{~cm}^{2}$. Ultraflux ${ }^{\circledR}$ AV $1000 \mathrm{~S}$ module was a hemofilter consisted of 10,258 hollow fibers with an effective length of $254 \mathrm{~mm}$, an internal diameter of $220 \mu \mathrm{m}$ and a wall thickness of $35 \mu \mathrm{m}$, installed inside a polycarbonate shell. An effective membrane area of the module was $1.8 \mathrm{~m}^{2}$. MF was performed using a Kerasep W5 ceramic membrane (Tech-Sep, Mirabel, France) with a nominal pore size of $0.2 \mu \mathrm{m}$. Kerasep membrane consisted of 19 cylindrical channels of $4 \mathrm{~mm}$ inner diameter, $270 \mathrm{~cm}$ effective length, and $644 \mathrm{~cm}^{2}$ total membrane area. The membrane was cleaned by dipping it into a hot solution consisted of $1 \%(\mathrm{w} / \mathrm{w}) \mathrm{NaOH}$ and $1 \mathrm{M} \mathrm{NaClO}$ for $30 \mathrm{~min}$. Acid cleaning was not used because no improvement in the permeate flux recovery was observed.

\subsection{MF/UF procedure}

A diagram of the MF/UF rig used in this work is shown in Fig. 2. A pasteurized raw juice (sample 3) was fed in the holding tank and brought into circulation through the module using a membrane pump. Transmembrane pressure was controlled by two back-pressure valves installed in the main retentate line and bypass line. In all UF runs, the transmembrane pressure and temperature were kept constant at 1 bar and $22^{\circ} \mathrm{C}$, respectively and a flow rate of the retentate stream was $11 \mathrm{~min}^{-1}$. The permeate was returned back to the holding tank to keep a constant volume of the retentate.

In MF runs, the transmembrane pressure and temperature were kept constant at $0.5-3$ bar and $22-55^{\circ} \mathrm{C}$, respectively. The juice temperature was adjusted by passing the retentate from a bypass line through the thermostat bath. Two different operating modes were used in MF: (a) Closed-loop recirculation of the retentate stream with a recycle of the permeate back to the feed tank to keep the retentate volume constant; (b) closedloop recirculation of the retentate with no permeate recycle to allow haze particles to concentrate. The mass of permeate collected in a reservoir placed on a digital balance was measured every $1 \mathrm{~min}$ for periods of $120 \mathrm{~min}$ and converted to volume based on the permeate density. The membrane backwashing every 6 or 10 min was done in some MF runs. This was achieved by forcing air at 0.5 bar gauge pressure to flow through the membrane in the opposite direction, which helped to lift and remove rejected solids from the inner surface of the membrane. The duration of the backflow was $60 \mathrm{~s}$ during which time cross flow was discontinued.

\subsection{Juice analysis}

Juice samples were analyzed for $\mathrm{pH}$, soluble solids, titratable acidity, total sugars, pectin, $\beta$-glucan, total anthocyanins, density and viscosity. Soluble solids were measured by a Krüss HRN32 hand refractometer with an accuracy of $\pm 0.2 \% \mathrm{Bx}$ and $\mathrm{pH}$ was determined by a potentiometric method. Total sugars were determined by Luff-Schoorl method, which is based on iodometric determination of the unreduced $\mathrm{Cu}$ (II) ions remaining after the reaction with reducing sugars (Egan et al., 1981). Titratable acidity expressed as anhydrous citric acid was determined by titrating a sample with $0.1 \mathrm{M} \mathrm{NaOH}$. The pectin concentration was measured using the carbazole method (Bitter and Muir, 1962). The presence of $\beta$-glucans was checked by the ethanol precipitation test (DSM, 2011). The density and viscosity of the juice was measured using a Westphal balance and Oswald viscometer, respectively. The total anthocyanins were determined by the spectrophotometric method of Somers and Evans (1977).

\section{Results and discussion}

\subsection{The effect of processing on the clarity of red raspberry juice}

Table 1 shows the chemical composition of defrosted red raspberry, raw juice after pasteurization and clarified juice obtained by MF. Virtually all total soluble solids and citric acid of the raw juice were recovered in the MF permeate, which was due to their small molecular size compared to the pore size. $\beta$-Glucans were not present neither in defrosted fruit nor in juices. $\beta$-Glucans are polymers found in the cellular walls of bacteria, fungi and yeasts and they are present in raspberry juice if the fruit was infected with Botrytis and Leuconostoc sp. $\beta$-Glucans make the juice highly viscous, causing the difficulties in juice extraction and clarification and thus, if present, they should be broken down to D-glucose during enzymatic maceration. The amount of total pectins in the defrosted red raspberry was $2.98 \mathrm{gl}^{-1}$, but after maceration it was reduced to $0.9 \mathrm{gl}^{-1}$, as a result of enzymatic degradation of pectin. The residual pectin was completely removed from the juice by MF (Table 1) and UF (the results are not shown here). As a result of the removal of macromolecules (cellulose, hemicelluloses, starch, pectin, etc.) from the juice during MF, the viscosity of the juice was reduced from 1.52 to $1.24 \mathrm{mPa}$ s, which was associated with the reduction of density from 1049 to $1040 \mathrm{~kg} \mathrm{~m}^{-3}$.

The effect of clarification procedure on the clarity of raspberry juice is shown in Fig. 3. The juice clarity was measured 
Table 1 - Composition and physical properties of defrosted raspberry, raw juice after pasteurization but prior to clarification, and clarified juice produced by MF.

\section{Crushed fruit \\ (sample 1) ${ }^{\mathrm{a}}$}

Pre-treated raw

juice (sample 3)
Juice clarified by

MF (sample 4 g)

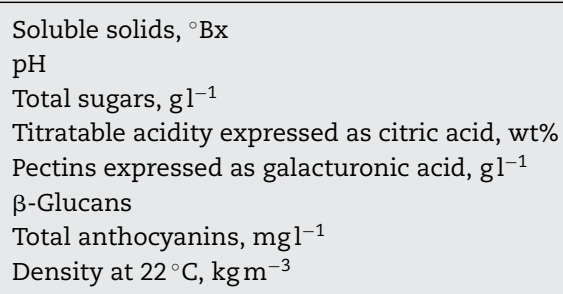

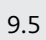

9.5

3.2

85

2.50

0.90

No

630

1049

1.52

9.4

84

0

No

540

1040

1.24

a The sample points are shown in Fig. 1.

as light transmittance at a wavelength of $625 \mathrm{~nm}$ (T625). Clarification of fruit juice with gelatin and bentonite is a common industrial practice (Stocké, 1998). Particles causing turbidity are mainly composed of pectins, polyphenols, proteins and their complexes and they tend to be negatively charged. Therefore, a positively charged protein, gelatin, is added to neutralize the charges so the haze particles will then clump with gelatin and settle out. Bentonite is a negatively charged clay used to remove any residual gelatin. In this work, 36 or $65 \mathrm{mgl}^{-1}$ gelatin was added, followed by $1000 \mathrm{mgl}^{-1}$ bentonite, which resulted in T625 values of 80 and $82 \%$, respectively. These $\mathrm{T} 625$ values are close to $80 \%$, which is the minimum acceptable level of light transmission in a commercial clear fruit juice (the dashed line in Fig. 3) (personal communication, 2013).

As shown in Fig. 3, raspberry juice clarified by membrane filtration was less turbid than that treated with bentonite and gelatin. A microfiltered juice was more turbid than ultrafiltered juices, presumably because UF can remove smaller haze particles than MF. As expected, the highest turbidity in an

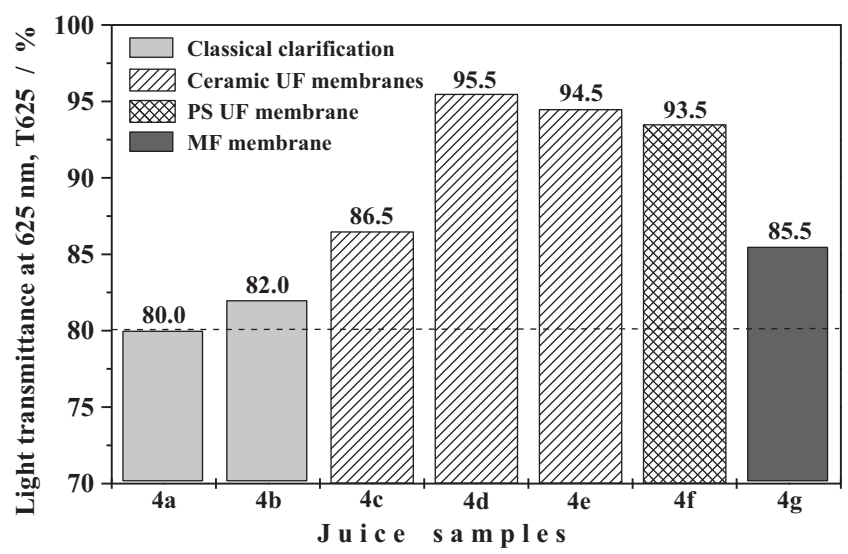

Fig. 3 - A percent light transmittance at $625 \mathrm{~nm}$ wavelength in red raspberry juice clarified using different methods: $4 \mathrm{a}=$ treatment with $3.6 \mathrm{~g} \mathrm{hl}^{-1}$ gelatin and $100 \mathrm{~g} \mathrm{hl}^{-1}$ bentonite; $4 \mathrm{~b}=$ treatment with $6.5 \mathrm{~g} \mathrm{hl}^{-1}$ gelatin and $100 \mathrm{~g} \mathrm{hl}^{-1}$ bentonite; $4 \mathrm{c}=\mathrm{UF}$ using a ceramic membrane with $300 \mathrm{kDa}$ MWCO; $4 \mathrm{~d}=\mathrm{UF}$ using a ceramic membrane with $50 \mathrm{kDa}$ MWCO; $4 \mathrm{e}=$ UF using a ceramic membrane with $30 \mathrm{kDa}$ MWCO; $4 \mathrm{f}=\mathrm{UF}$ using a polysulfone membrane with $30 \mathrm{kDa}$ MWCO; $4 \mathrm{~g}=$ MF using a ceramic membrane with $0.2 \mu \mathrm{m}$ pore size. The minimum acceptable light transmittance in a clear raspberry juice for market is shown by the dashed line. ultrafiltered juice was found in the juice clarified using the membrane with a MWCO of $300 \mathrm{kDa}$. No significant difference in light transmission was found in the juices clarified using the membrane with a MWCO of 30 and $50 \mathrm{kDa}$, which indicates that virtually all haze particles are rejected by the membrane with a MWCO of $50 \mathrm{kDa}$.

\subsection{Recovery of total anthocyanins during processing}

The impact of different stages of juice processing on the content of total anthocyanins is shown in Fig. 4. Anthocyanins are plant pigments localized in the cell vacuole. When raspberries are crushed to a pulp, the cell membrane breaks causing the vacuole to release the anthocyanin, but some plant cells stay intact. Due to additional enzymatic and mechanical degradation of the cellular wall during maceration and pressing, the anthocyanin was released from these intact cells causing an increase in the anthocyanin content from 650 to $670 \mathrm{mgl}^{-1}$. A subsequent drop in the anthocyanin content from 670 to $630 \mathrm{mgl}^{-1}$ was a consequence of heat degradation during pasteurization. The content of anthocyanin was reduced by

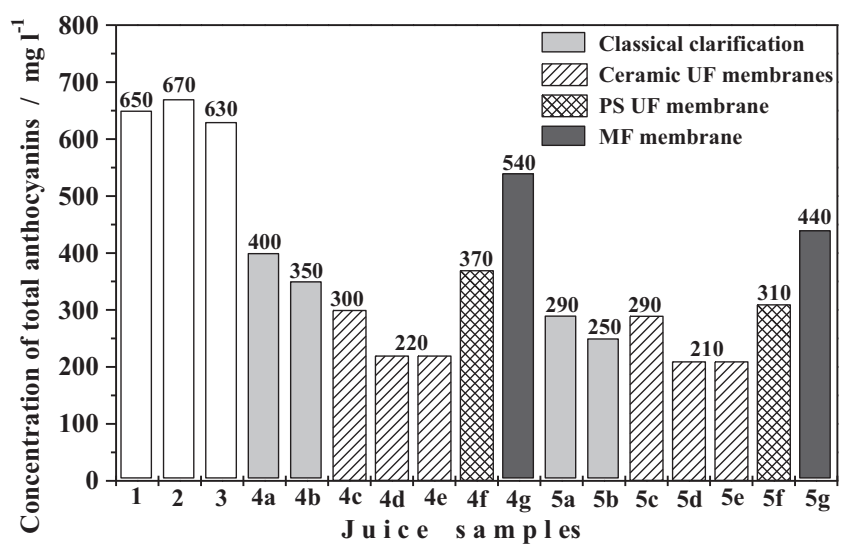

Fig. 4 - The content of total anthocyanins during juice processing: 1 = after fruit crushing; 2 = after juice extraction; $3=$ after pasteurization; $4 \mathrm{a}=$ after fining with $36 \mathrm{mg} \mathrm{l}^{-1}$ gelatin and $1000 \mathrm{mg} \mathrm{l}^{-1}$ bentonite; $4 \mathrm{~b}=$ after fining with $65 \mathrm{mgl}^{-1}$ gelatin and $1000 \mathrm{mg} \mathrm{l}^{-1}$ bentonite; $4 \mathrm{c}=$ after UF using a ceramic membrane with $300 \mathrm{kDa}$ MWCO; $4 \mathrm{~d}=$ after UF using a ceramic membrane with $50 \mathrm{kDa}$ MWCO; $4 e=$ after UF using a ceramic membrane with $30 \mathrm{kDa}$ MWCO; $\mathbf{4 f}$ = after UF using a polysulfone membrane with $30 \mathrm{kDa}$ MWCO; $4 \mathrm{~g}=$ after MF using a membrane with $0.2 \mu \mathrm{m}$ pore size; $5 \mathrm{a}=$ juice reconstituted from sample $4 \mathrm{a}$; $5 b=$ juice reconstituted from sample $4 b$, etc. 


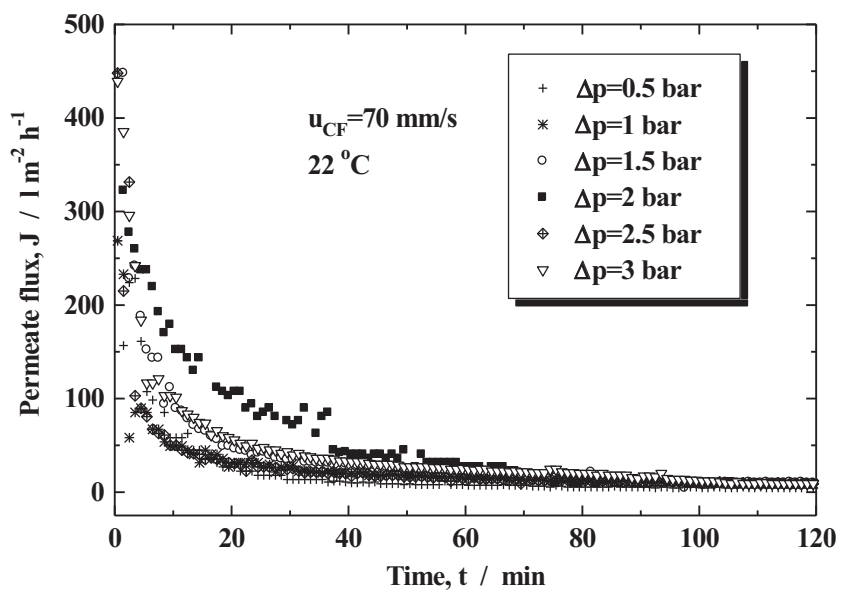

Fig. 5 - The variation of permeate flux with time at different transmembrane pressures for MF of red raspberry juice at $22^{\circ} \mathrm{C}$ and cross flow velocity of $70 \mathrm{~mm} / \mathrm{s}$. The permeate was recycled back to the holding tank to keep $\mathrm{VCF}=1$.

$36-44 \%$ during fining with gelatin and bentonite. A higher amount of anthocyanin was removed when a larger amount of gelatin was added, indicating that anthocyanins in the juice were bound to gelatin. The primary reaction between anthocyanins and gelatin is a complex formation caused by hydrogen bonding between the hydroxyl groups of anthocyanidins and the $\mathrm{O}$ and $\mathrm{N}$ atoms of the keto and amino acid groups of gelatin (Benitez and Lozano, 2007).

The content of anthocyanin was reduced by $65 \%$ when the juice was ultrafiltered through ceramic membranes with a MWCO of 30 and $50 \mathrm{kDa}$. A loss of anthocyanins was smaller when the juice was clarified using polysulfone than ceramic Carbosep M7 membrane, although both membranes have the same MWCO. It may indicate that anthocyanins are rejected by UF membrane not only as a result of molecular size exclusion but also due to physicochemical interactions with the membrane wall. It may be that anthocyanins have higher binding affinity to sintered inorganic oxides particles in the active layer of Carbosep membrane than to organic polymers.

The maximum content of anthocyanins in both a fresh and reconstituted clear juice was obtained by MF. A loss of anthocyanins during evaporation (from 540 to $440 \mathrm{mgl}^{-1}$ in MF permeate) was due to thermal decomposition of anthocyanins, caused by oxidation reactions and/or cleavage of covalent bonds in the flavylium ion. The initial step in this degradation process is hydrolysis of sugar moiety and aglycone formation or opening of the pyrylium ring and chalcone formation (Patras et al., 2010).

Based on the above results, MF was selected as a method of choice for clarification of red raspberry juice, because it allows maximum recovery of anthocyanins both in a clear and reconstituted juice, a better light transmission than in the juices clarified with traditional fining agents, and offer higher permeate fluxes, compared to UF. Another advantage of MF over MF is that it requires lower transmembrane pressures which may bring additional economic benefits.

\subsection{Microfiltration of red raspberry juice}

Fig. 5 shows the variations of the permeate flux with time obtained during MF at different transmembrane pressures. The permeate fluxes were calculated by numerical differentiation of the permeate mass vs. time data. The flux curve

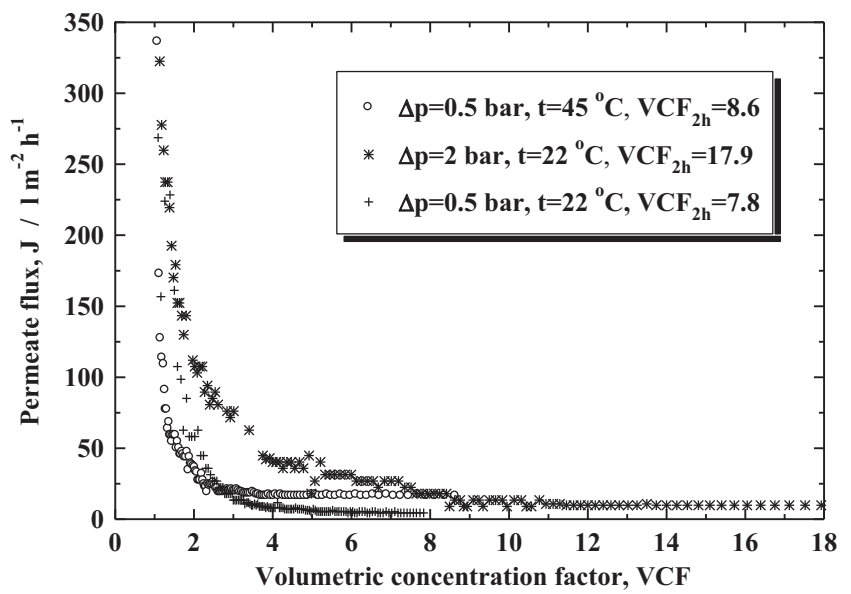

Fig. 6 - The permeate flux as a function of volumetric concentration factor at different transmembrane pressures. The volumetric concentration factor obtained after $2 \mathrm{~h}$ $\left(\mathrm{VCF}_{2 \mathrm{~h}}\right)$ at different operating conditions was indicated in the legend. The initial volume of the juice was 8.51 .

can be divided into two domains (Lahoussine-Turcaud et al., 1990). Domain 1 corresponds to the initial rapid flux decline for $t \rightarrow 0$ caused by a build-up of the concentration boundary layer and internal fouling. Domain 2 corresponds to the remaining flux decline and mainly involves external membrane fouling (Mondor et al., 2000). In Fig. 5, the permeate flux in the first minute of operation was $25-91 \%$ of the initial flux given by $\Delta p /\left(\eta_{p} R_{m}\right)$, where $\eta_{p}=1.24 \mathrm{mPa}$ s is the permeate viscosity (Table 1) and $R_{m}=4.96 \times 10^{11} \mathrm{~m}^{-1}$ is the hydrodynamic resistance of Kerasep membrane. The most significant flux decline in the first minute was observed at the highest pressure of 3 bar, due to the highest rate of accumulation of the rejected solids onto the membrane surface. A steady state was established after $80 \mathrm{~min}$ when the rate of convective transport of haze particles toward the membrane surface was balanced by the rate of particle transport away from the membrane. The permeate flux at steady state was about $101 \mathrm{~m}^{-2} \mathrm{~h}^{-1}$ and independent on the transmembrane pressure, as predicted by the gel-polarization model (Porter, 1972). A maximum permeate flux in the unsteady state portion of the graph was obtained at the pressure of 2 bar, which is a type of behavior observed earlier in UF of apple juice (Vladisavljević et al., 2003) and pear juice (Kirk et al., 1983). Haze particles of fruit juice are voluminous aggregates of polymerized polyphenol or polyphenol-protein complexes (Beveridge and Tait, 1993). At sufficiently high pressures, these large aggregates are disrupted into much smaller particles forming a less porous and more compact layer on the membrane surface. Another explanation for the existence of maximum flux at 2 bar is a collapse in hydrogen bond bridges between pectin macromolecules at the pressures above 2 bar, which leads to the closure of interstitial spaces between the pectin chains in the cake (Kirk et al., 1983).

Fig. 6 shows the variations of the permeate flux with the volume concentration factor over $2 \mathrm{~h}$ of operation. The permeate was not recycled back to the holding tank so as to allow the rejected particles to concentrate in the retentate stream. A volume concentration factor (VCF) was calculated as the initial juice volume divided by the retentate volume at any time: $\mathrm{VCF}=\mathrm{V}_{0} /\left(\mathrm{V}_{0}-\mathrm{V}_{p}\right)$, where $\mathrm{V}_{0}$ is the initial juice volume and $V_{p}$ is the permeate volume. The graph shown in Fig. 6 can be divided into three regions: region $1(\mathrm{VCF}=1-2)$ extending 


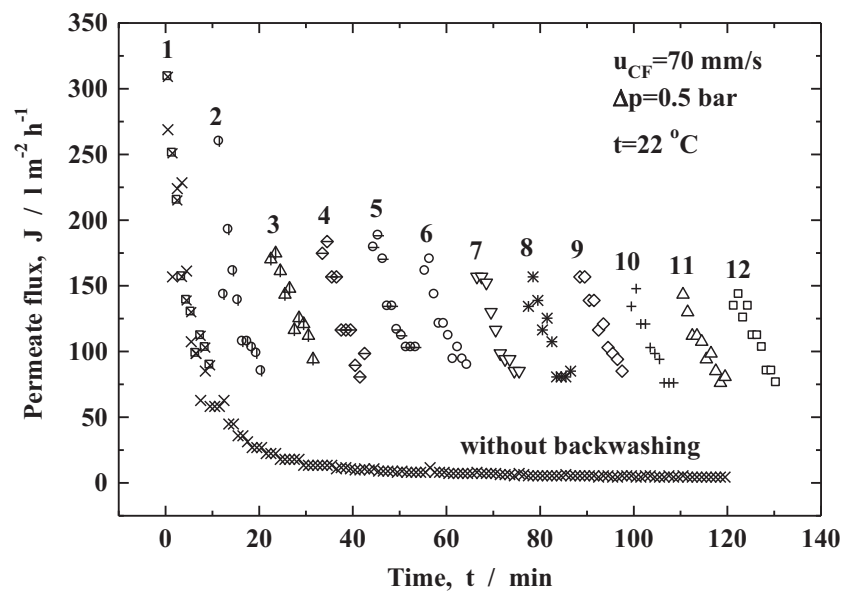

Fig. 7 - A comparison of permeate flux fluctuations with time during MF without and with air backwashing for $1 \mathrm{~min}$ every $10 \mathrm{~min}$. The gauge pressure of air during backwashing was 0.5 bar.

over a period of about 10 min where the permeate flux rapidly declines with VCF, region 2 (VCF = 3-7) where the flux continues to decline but at a significantly reduced rate, and region 3 (VCF > 7) where the flux decline is so slow that a quasi-steady state operation may be assumed. A maximum $\mathrm{VCF}_{2 \mathrm{~h}}$ value of 17.9 was achieved at the pressure of 2 bar for the initial juice volume of $8.5 \mathrm{l}$, indicating that more than $8 \mathrm{l}$ of clear juice were produced after $2 \mathrm{~h}$. When the temperature increased from 22 to $45^{\circ} \mathrm{C}$, only a small increase in $\mathrm{VCF}_{2 \mathrm{~h}}$ was observed, because a positive effect of higher temperature on the permeate flux in region 3 was neutralized by a negative effect of the more rapid flux decline in region 1 , due to faster accumulation of solids at the higher temperature. The permeate flux at quasisteady state (period 3) at $45^{\circ} \mathrm{C}$ was higher than that at $25^{\circ} \mathrm{C}$ due to higher mass transfer coefficient of rejected solids, as predicted by the gel polarization model (Porter, 1972).

In the fruit juice industry, VCF values during juice clarification should exceed 20 and thus, most of the time MF is operated at quasi steady state, where the permeate flux is only a small fraction of its initial value. In order to avoid operation of MF in region 3 and yet to achieve acceptable VCFs required in practical applications, the microfilter was switched from filtration to backwashing mode every $10 \mathrm{~min}$ (at the end of region 1 ) for $1 \mathrm{~min}$. Fig. 7 compares the fluctuations of the permeate flux with time during MF with and without backwashing. When the membrane was backwashed, there were 12 filtration cycles. After first backwashing, the permeate flux was improved from 92 to $260 \mathrm{~lm}^{-2} \mathrm{~h}^{-1}$, but the initial flux of $290 \mathrm{l} \mathrm{m}^{-2} \mathrm{~h}^{-1}$ was not restored. It can be explained by irreversible membrane fouling, i.e. a strong attachment of particles to the membrane surface that requires chemical reagents to be mitigated (Choi et al., 2005). After second backwashing, the permeate flux was improved from 85 to $175 \mathrm{~lm}^{-2} \mathrm{~h}^{-1}$, but it was below the level at the start of the previous filtration cycle $\left(260 \mathrm{l} \mathrm{m}^{-2} \mathrm{~h}^{-1}\right)$, pointing out to further progression of irreversible membrane fouling. From cycle 3 onwards, the permeate flux after each backwashing step was approximately equal to or slightly less than the flux at the start of the previous filtration cycle. It suggests that the membrane surface has a finite number of available binding sites to which haze particles can attach irreversibly. After first backwashing, the fouling resistance due to irreversible fouling $\left(R_{f i}\right)$ was $0.13 R_{m}$ and after last backwashing, $R_{f i}$ was equal to $R_{m}$.

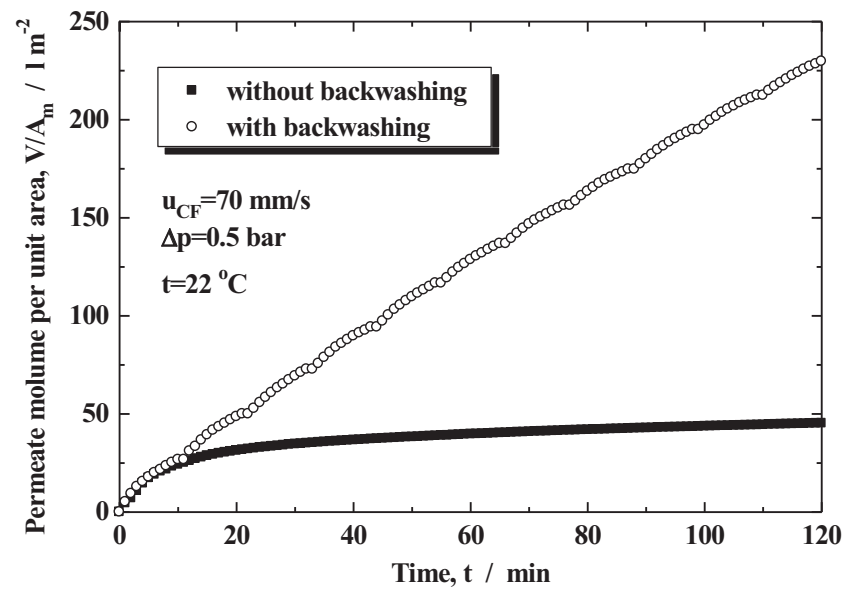

Fig. 8 - The permeate flux collected per unit membrane area as a function of time during MF of red raspberry juice without backwashing and with air backwash every $10 \mathrm{~min}$ for $1 \mathrm{~min}$. The gauge pressure of air during backwashing was 0.5 bar.

In Fig. 8, the permeate volume collected per unit membrane area was plotted against time for MF conducted at 0.5 bar with and without backwashing. In the absence of backwashing, the fouling resistance continuously increased with time until a steady state was established. At steady state, the overall fouling resistance $\left(R_{f i}+R_{f r}\right)$ was $65 R_{m}$, which can be attributed mainly to reversible fouling, because $R_{f} \approx R_{m}$. For a MF operated with backwashing, due to removal of reversible fouling every $10 \mathrm{~min}$, the overall fouling resistance was maintained below $2.8 R_{m}$. As can be seen in Fig. 8, when the membrane was backwashed, after $2 \mathrm{~h}$ more than 5 times greater amount of permeate was collected at the same pressure.

Fig. 9 shows the effect of transmembrane pressure on the permeate flux during MF with backwashing. The membrane was backwashed every $6 \mathrm{~min}$ to avoid a negative effect of cake compaction at $\Delta p>2$ bar on the fouling resistance over prolonged time (Fig. 5). At $\Delta p=3$ bar, the permeate flux after backwashing was not fully restored to the initial value of $385 \mathrm{~lm}^{-2} \mathrm{~h}^{-1}$ due to irreversible membrane fouling, but yet it was maintained at relatively high levels between 170 and

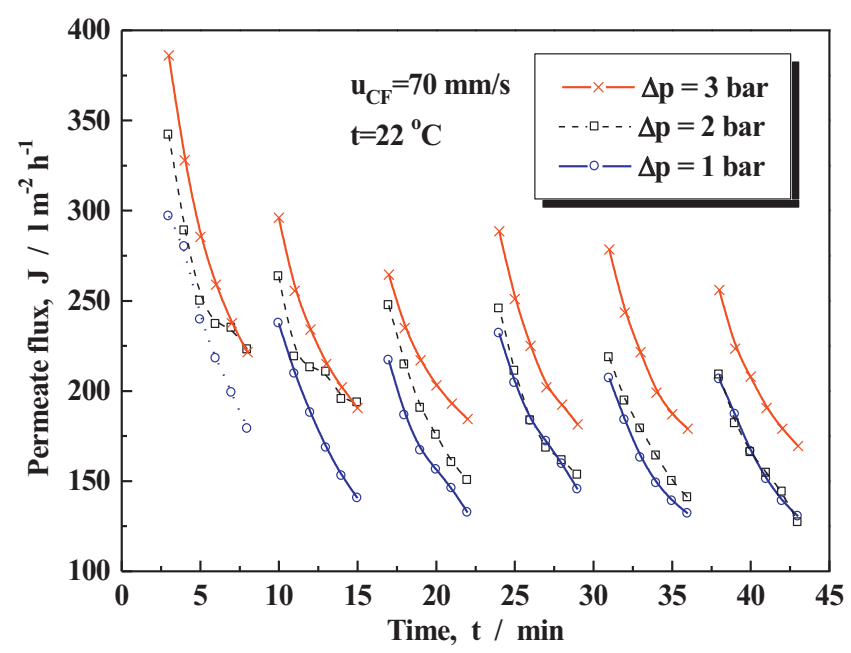

Fig. 9 - The variation of permeate flux with time at three different transmembrane pressures during MF with air backwashing. The membrane was backwashed with air at the gauge pressure of 0.5 bar every $6 \mathrm{~min}$ for $1 \mathrm{~min}$. 
$300 \mathrm{~lm}^{-2} \mathrm{~h}^{-1}$. The permeate flux at 3 bar was greater than that observed at 2 bar, suggesting that the cake compression was prevented by a short duration of filtration cycles.

\section{Conclusions}

Clarification of red raspberry ( $R$. idaeus) juice was investigated for the first time using cross flow membrane filtration (MF or UF). A loss of anthocyanins in fresh and reconstituted clear juice was much smaller when the juice clarification was done using MF than by flocculation with gelatin and bentonite. After MF through multichannel ceramic membrane with a pore size of $0.2 \mu \mathrm{m}$, only a minimal loss of anthocyanins was observed, the residual pectin was completely removed and a light transmission at $625 \mathrm{~nm}$ was in excess of $85 \%$. UF can be used to obtain a crystal clear juice with a light transmission at $625 \mathrm{~nm}$ exceeding $95 \%$, but it must be paid by a significant loss of anthocyanins. The permeate flux in MF was maintained at high levels above $170 \mathrm{~lm}^{-2} \mathrm{~h}^{-1}$ for more than $2 \mathrm{~h}$ by periodic gas backwashing and the cake compression at high pressures was prevented by using sufficiently high backwashing frequency. The results obtained in this work show that microfiltration with periodic gas backwashing is a viable strategy for producing fresh and reconstituted clear red raspberry juice of desirable sensory properties and nutritional value.

\section{References}

Aehle, W., 2007. Enzyme in Industry: Production and Applications, 3rd ed. Wiley-WCH, Weinheim, pp. 99-262.

Beveridge, T., Tait, V., 1993. Structure and composition of apple juice haze. Food Struct. 12 (2), 195-198.

Benitez, E.I., Lozano, J.E., 2007. Effect of gelatin on apple juice turbidity. Latin Am. Appl. Res. 37 (4), 261-266.

Bitter, T., Muir, H.M., 1962. A modified uronic acid carbazole reaction. Anal. Biochem. 4 (4), 330-334.

Brenna, O., Pompei, C., Ortolani, C., Pravettoni, V., Pastorello, E.A., Farioli, L., 2000. Technological processes to decrease the allergenicity of peach juice and nectar. J. Agric. Food Chem. 48 (2), 493-497.

Cassano, A., Donato, L., Conidi, C., Drioli, E., 2008. Recovery of bioactive compounds in kiwifruit juice by ultrafiltration. Innov. Food Sci. Emerg. Technol. 9 (4), 556-562.

Choi, H., Zhang, K., Dionysiou, D.D., Oerther, D.B., Sorial, G.A., 2005. Effect of permeate flux and tangential flow on membrane fouling for wastewater treatment. J. Sep. Purif. Technol. 45 (1), 68-78.

DSM, 2011. Fruit Processing Ingredients, Solutions to Optimise Fruit Processing Worldwide. DSM Food Specialties Beverage Ingredients, Lille, France.

Egan, H., Kirk, R., Sawyer, R., 1981. The Luff Schoorl method. Sugars and preserves. In: Pearson's Chemical Analysis of Foods, 8th ed. Longman Scientific and Technical, Harlow, UK, pp. 152-153.

Espamer, L., Pagliero, C., Ochoa, A., Marchese, J., 2006. Clarification of lemon juice using membrane process Desalination 200 (1-3), 565-567.

Girard, B., Fukumoto, L.R., 2000. Membrane processing of fruit juices and beverages: a review. Crit. Rev. Food Sci. Nutr. 40 (2), 91-157.

Gupta, B.B., Blanpain, P., Jaffrin, M.Y., 1992. Permeate flux enhancement by pressure and flow pulsations in microfiltration with mineral membranes. J. Membr. Sci. 70 (2-3), 257-266.

Kirk, D.E., Montgomery, M.W., Kortekaas, M.G., 1983. Clarification of pear juice by hollow fibber ultrafiltration. J. Food Sci. 48 (6), 1663-1666.

Koroknai, B., Csanádi, Z., Gubicza, L., Bélafi-Bakó, K., 2008. Preservation of antioxidant capacity and flux enhancement in concentration of red fruit juices by membrane processes. Desalination 228 (1-3), 295-301.

Lahoussine-Turcaud, V., Wiesner, M.R., Bottero, J.Y., 1990. J. Membr. Sci. 52 (2), 173-190.

Laorko, A., Li, Z., Tongchitpakdee, S., Youravong, W., 2011. Effect of gas sparging on flux enhancement and phytochemical properties of clarified pineapple juice by microfiltration. Sep. Purif. Technol. 80 (3), 445-451.

Mejia-Meza, E.I., Yáñez, J.A., Remsberg, C.M., Takemoto, J.K., Davies, N.M., Rasco, B., Clary, C., 2010. Effect of dehydration on raspberries: polyphenol and anthocyanin retention, antioxidant capacity, and antiadipogenic activity. J. Food Sci. 75 (1), 5-12.

Mondor, M., Girard, B., Moresoli, C., 2000. Modeling flux behavior for membrane filtration of apple juice. Food Res. Int. 33 (7), 539-548.

Padilla-Zakour, O., McLellan, M.R., 1993. Optimization and modeling of apple juice cross-flow microfiltration with a ceramic membrane. J. Food Sci. 58 (2), 369-388.

Pal, S., Ambastha, S., Ghosh, T.B., De, S., DasGupta, S., 2008. Optical evaluation of deposition thickness and measurement of permeate flux enhancement of simulated fruit juice in presence of turbulence promoters. J. Membr. Sci. 315 (1-2), 58-66.

Pap, N., Mahosenaho, M., Pongrácz, E., Mikkonen, H., Jaakkola, M., Virtanen, V., Myllykoski, L., Horváth-Hovorka, Z., Hodúr, C., Vatai, G., Keiski, R.L., 2012. Effect of ultrafiltration on anthocyanin and flavonol content of blackcurrant juice (Ribes nigrum). Food Bioprocess Technol. 5 (3), 921-928.

Patras, A., Brunton, N.P., O’Donnell, C., Tiwari, B.K., 2010. Effect of thermal processing on anthocyanin stability in foods; mechanisms and kinetics of degradation. Trends Food Sci. Technol. 21 (1), 3-11.

Porter, M.C., 1972. Concentration polarization with membrane ultrafiltration. Ind. Eng. Chem. Product Res. Develop. 11 (3), 234-248.

Puupponen-Pimiä, R., Nohynek, L., Hartmann-Schmidlin, S. Kähkönen, M., Heinonen, M., Määttä-Riihinen, K., Oksman-Caldentey, K.M., 2005. Berry phenolics selectively inhibit the growth of intestinal pathogens. J. Appl. Microbiol. 98 (4), 991-1000.

Rai, P., Majumdar, G.C., Gupta, S.D., De, S., 2007. Effect of various pretreatment methods on permeate flux and quality during ultrafiltration of mosambi juice. J. Food Eng. 78 (2), 561-568.

Rai, C., Rai, P., Majumdar, G.C., De, S., Gupta, S.D., 2010. Mechanism of permeate flux decline during microfiltration of watermelon (Citrullus lanatus) juice. Food Bioprocess Technol. 3 (4), 545-553.

Rektor, Pap, A., Kókai, N., Szabó, Z., Vatai, R., Békássy-Molnár, G., 2004. Application of membrane filtration methods for must processing and preservation. Desalination 162, 271-277.

Rouanet, J.M., Décordé, K., Rio, D.D., Auger, C., Borges, G., Cristol, J.P., Lean, M.E.J., Crozier, A., 2010. Berry juices, teas, antioxidants and the prevention of atherosclerosis in hamsters. Food Chem. 118 (2), 266-271.

Sarkar, B., De, S., Gupta, S.D., 2008a. Pulsed electric field enhanced ultrafiltration of synthetic and fruit juice. Sep. Purif. Technol. 63 (3), 582-591.

Sarkar, B., Gupta, S.D., De, S., 2008b. Cross-flow electro-ultrafiltration of mosambi (Citrus sinensis (L.) Osbeck) juice. J. Food Eng. 89 (2), 241-245.

Seeram, N.P., 2008. Berry fruits for cancer prevention: current status and future prospects. J. Agric. Food Chem. 56 (3), 630-635.

Snir, R., Koehler, P.E., Sims, K.A., Wicker, L., 1995. pH and cations influence permeability of marsh grapefruit pectinesterase on polysulfone ultrafiltration membrane. J. Agric. Food Chem. 43 (5), 1157-1162.

Somers, T.C., Evans, M.E., 1977. Spectral evaluation of young red wine, anthocyanin equilibrium, total phenolic, free and molecular $\mathrm{SO}_{2}$. J. Sci. Food Agric. 28 (3), 279-287.

Stocké, R., 1998. The 3-component stabilization with bentonite, gelatin and silica sol. Fruit Process. 1, 6-10. 
Su, S.K., Liu, J.C., Wiley, R.C., 1993. Cross-flow microfiltration with gas backwashing of apple juice. J. Food Sci. 58 (3), 638-641.

Suh, J.H., Romain, C., Gonzáles-Barrio, R., Cristol, J.P., Teissèdre, P.L., Crozer, A., Rouanet, J.M., 2011. Raspberry juice consumption, oxidative stress and reduction of atherosclerosis risk factors in hypercholesterolemic golden Syrian hamsters. Food Funct. 2 (7), 400-405.

Sulaiman, M.Z., Sulaiman, N.M., Yih, L.S., 1998. Limiting permeate flux of untreated starfruit juice by membrane ultrafiltration. Chem. Eng. J. 69 (2), 145-148.

Ushikubo, F.Y., Watanabe, A.P., Viotto, L.A., 2007. Microfiltration of umbu (Spondias tuberosa Arr. Cam.) juice. J. Membr. Sci. 288 (1-2), 61-66.

Vaillant, F., Millan, P., O’Brien, G., Dornier, M., Decloux, M., Reynes, M., 1999. Crossflow microfiltration of passion fruit juice after partial enzymatic liquefaction. J. Food Eng. 42 (4), 215-224.

Vaillant, F., Millan, A., Dornier, M., Decloux, M., Reynes, M., 2001. Strategy for economical optimisation of the clarification of pulpy fruit juices using crossflow microfiltration. J. Food Eng. 48 (1), 83-90.

Vaillant, F., Cisse, M., Chaverri, M., Perez, A., Dornier, M., Viquez, F., Dhuique-Mayer, C., 2005. Clarification and concentration of melon juice using membrane processes. Innov. Food Sci. Emerg. Technol. 6 (2), 213-220.
Vaillant, F., Pérez, A.M., Acosta, O., Dornier, M., 2008. Turbidity of pulpy fruit juice: a key factor for predicting cross-flow microfiltration performance. J. Membr. Sci. 325 (1), 404-412.

Vladisavljević, G.T., Vukosavljević, P., Bukvić, B., 2003. Permeate flux and fouling resistance in ultrafiltration of depectinized apple juice using ceramic membranes. J. Food Eng. 60 (3), 241-247.

Wang, B.J., Wei, T.C., Yu, Z.R., 2005. Effect of operating temperature on component distribution of West Indian cherry juice in a microfiltration system. LWT - Food Sci. Technol. 38 (6), 683-689.

Weber, C., Liu, M., Li, X.Q., Liu, R.H., 2001. Antioxidant capacity and anticancer properties of red raspberry. N. Y. Fruit Quart. 9 (3), 13-15.

Yoruk, R., Marshall, M.R., 2003. Physicochemical properties and function of plant polyphenol oxidase: a review. J. Food Biochem. 27 (5), 361-422.

Youn, K.S., Hong, J.H., Bae, D.H., Kim, S.J., Kim, S.D., 2004. Effective clarifying process of reconstituted apple juice using membrane filtration with filter-aid pretreatment. J. Membr. Sci. 228 (2), 179-186.

Zafra-Stone, S., Yasmin, T., Bagchi, M., Chatterjee, A., Vinson, J.A., Bagchi, D., 2007. Berry anthocyanins as novel antioxidants in human health and disease prevention. Mol. Nutr. Food Res. 51 (6), 675-683. 